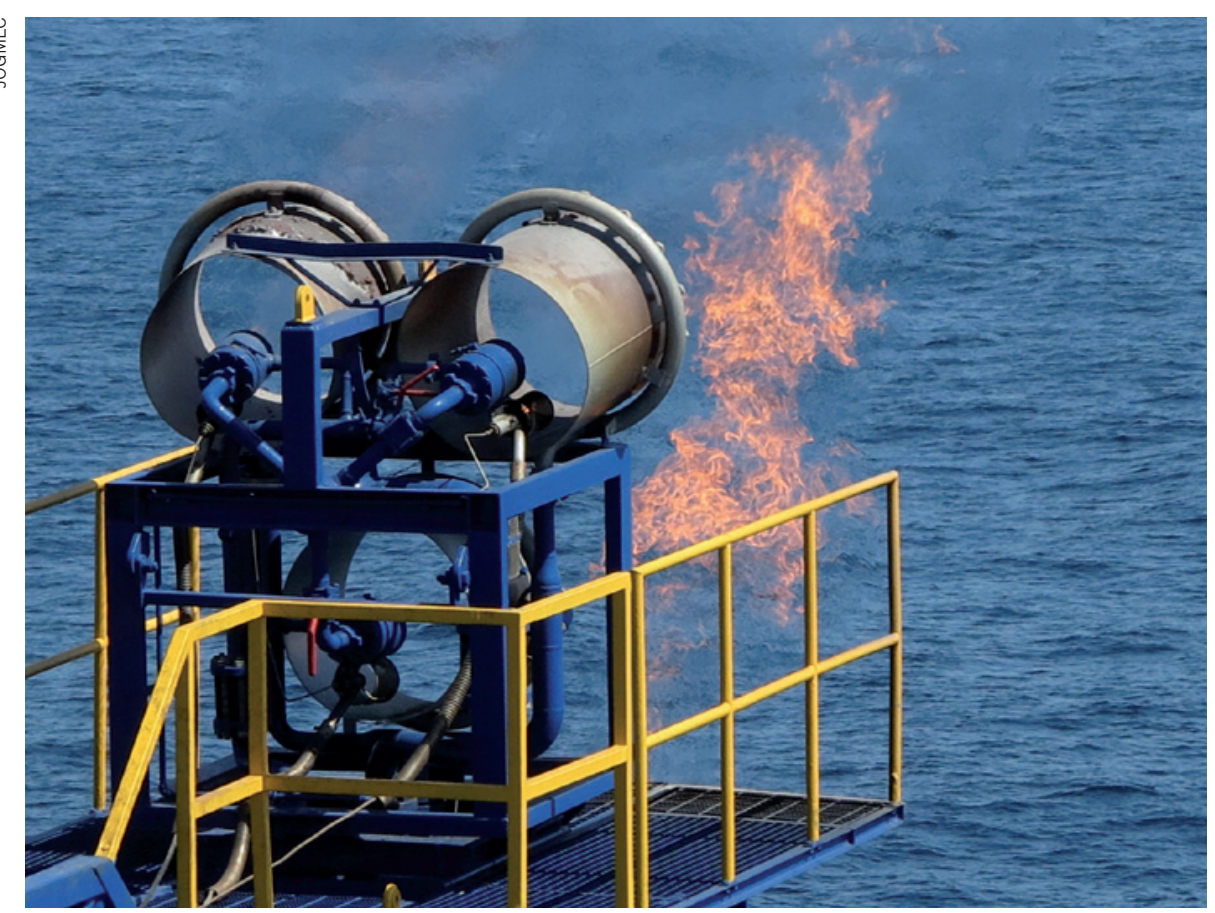

Methane being burnt off at sea after a team in Japan extracted the gas from frozen offshore deposits.

ENERGY

\section{Japanese test coaxes fire from ice}

\section{First attempt to extract methane from frozen hydrates far beneath the ocean shows promise.}

\section{BY DAVID CYRANOSKI}

$\mathrm{M}$ ethane flowing from beneath the sea floor has buoyed Japan's hopes for securing its own plentiful energy source. A pilot project 80 kilometres off the country's shores produced tens of thousands of cubic metres of gas - and reams of useful data - before a clogged pump brought the project to an abrupt end last month.

Reservoirs of methane hydrates - icy deposits in which methane molecules are trapped in a lattice of water - are thought to hold more energy than all other fossil fuels combined. The problem is extracting the methane economically from the deposits, which lie beneath Arctic permafrost and seafloor sediments. But some scientists and policymakers in energy-poor, coast-rich Japan hope that the reservoirs will become a crucial part of the country's energy profile.

Engineers have had some limited success in extracting methane from underneath Canadian tundra. But tapping the richer marine deposits presents a host of challenges, among them the fact that whereas oil and natural gas exist in deep reservoirs, methane hydrates are found in the first few hundred metres of the sea bottom where sediments are loose, making wells unstable and putting them at risk of clogging by sand.

The test, run by the Tokyo-based state oil company Japan Oil, Gas and Metals National Corporation (JOGMEC), took place in waters 1 kilometre deep, where the research drilling ship Chikyu had bored through 270 metres of sediment to reach a 60-metre-thick methane hydrate reservoir. On 12 March, a pump reduced the pressure in the deposit, unlocking the gas from its icy cage. Gas started flowing up from the sea floor to a platform on the ship, where it produced a roaring flame. "Being Japanese, you might have thought we would have yelled 'banzai' or something," says project director Koji Yamamoto. But he says that he was too busy staring at displays of crucial data showing the pressure at the bottom of the well and the flow rate and composition of the incoming gas.

\section{$\rightarrow$ NATURE.COM}

For more on extracting methane hydrates, see: go.nature.com/mobk76
The big question, and the one on which Japanese energy hopes depend, is whether the engineers can sustain the flow. They did - for a while. The methane flowed smoothly for six days, with the flow rate increasing as the pressure dropped, generating an average of 20,000 cubic metres a day - more than Yamamoto expected and ten times more than was produced by a well dug in Canadian permafrost in 2008 using the same depressurization method.

It is "a remarkable breakthrough", says Scott Dallimore, a geoscientist at the Geological Survey of Canada in Sidney, British Columbia, who worked on the Canadian project with JOGMEC but was not involved in the Japanese offshore test. "The engineering challenge to successfully undertake the test in a marine setting - was not insignificant. The flow rates are also very encouraging," he says.

Ray Boswell, technology manager for the methane hydrates programme at the US Department of Energy's National Energy Technology Laboratory in Morgantown, West Virginia, says that the test demonstrates that "what we have learned in the Arctic can be transferred to the marine environment, where the most significant resources are". From his experience of extracting methane from hydrates in Alaska, the team would have had to overcome significant obstacles, he says: the loose, shifting sediment, unpredictable weather and the fact that the methane cools its surroundings as it dissociates from the ice slush, potentially creating new hydrates that could slow production or clog up the well.

Yamamoto says that his team took care to avoid such problems. To stop the formation of icy hydrates, the researchers carefully lowered the pressure in the reservoir, aiming to cap it at 3 megapascals (MPa) by the end of the twoweek test to keep the methane in gas form. But on the sixth day, with the pressure down to 4.5 $\mathrm{MPa}$, the pump clogged up with sand and the test had to stop. "It was a disappointment," says Yamamoto. The team had used two sifting devices to try to prevent such a clog.

Yamamoto is confident that this and other obstacles can be overcome to create a steady supply of methane, but adds that improved extraction technologies and higher flow rates will be key to making the enterprise economically feasible. "We are 10 or 20 years behind shale, before they came up with fracking," he says. Others are not sure it is worth it. Canada and the United States have drastically cut their methane hydrate efforts, largely because they have plentiful gas from shale. Projects in China, India and South Korea, however, remain active.

The team will now examine temperature, seismic and other data to learn how far the dissociation of hydrates spread and thus how much methane they might expect to extract from one well. Yamamoto plans to spend a year preparing the next test, which he hopes will run for a further 12 months and will use more sophisticated monitoring.. 